Jürgens, A. (2009): Umsatzrekord für europäischen Fußball, in: Sponsors, 14, 7, S. 18-20.

Kaynak, E./Salman, G./Tatoglu, E. (2008): An integrative framework linking brand associations and brand loyalty in professional sports, in: Journal of Brand Management, 15, 5, pp. 336-357.

Ludwig, S./Schneider, C. P. (2008): Die wirtschaftliche Entwicklung deutscher Profiligen, in: Sponsors, 13, Sonderausgabe Clubmanager, S. 4-11.

Meenaghan, T. (2001): Understanding Sponsorship Effects, in: Psychology \& Marketing, 18, 2, pp. 95-122.

Sfip Nitschke, A. (2006): Der Event-Marken-Fit als Determinante der Kommunikationswirkung - eine Längsschnittbetrachtung am Beispiel der FIFA-Fußballweltmeisterschaft 2006, Wiesbaden.

Nufer, G. (2003): Der Imagetransfer im Event-Marketing, in: Jahrbuch der Absatzund Verbrauchsforschung, 49, S. 385-406.

Reinartz, W./Haenlein, M./Henseler, J. (2009): An empirical comparison of the efficacy of covariance-based and variance-based SEM, in: International Journal of Research in Marketing, 26, 4, pp. 332-344.

Sharma, S./Durand, R./Gur-Arie, O. (1981): Identification and Analysis of Moderator Variables, in: Journal of Marketing Research, 18., 3, pp. 291-300.

Welling, M. (2008): Vom Sponsoring zum Co-Branding?, in: Markenartikel, Sonderdruck aus „Sponsoring Boomt“, S. 2-7.

Zentes, J. (1996): Grundbegriffe des Marketing, Stuttgart.

*Abonnenten des Portals Springer für Professionals erhalten diesen Beitrag im Volltext unter www.springerprofessional.de.

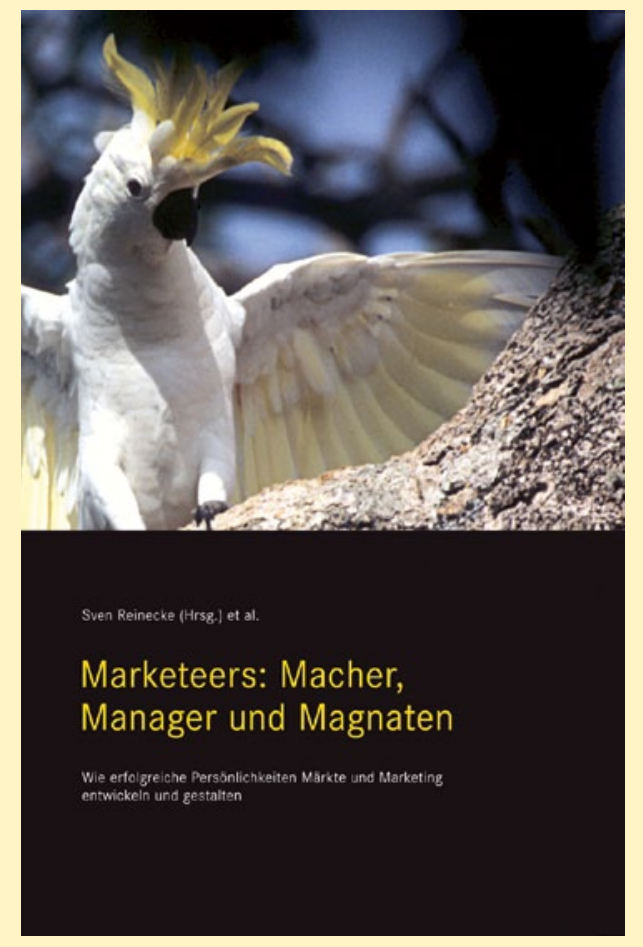

Sven Reinecke (Hrsg.) et al.

\title{
Marketeers: Macher, Manager und Magnaten
}

Wie erfolgreiche Persönlichkeiten Märkte und Marketing entwickeln und gestalten

«Markt gleich Menschen». Menschen interessieren sich primär für Menschen. Daher entschied sich das Marketingdepartement an der Universität St.Gallen (HSG), eine Publikation zu veröffentlichen, die den - neben dem Kunden - wichtigsten Menschen im Marketing in den Mittelpunkt stellt: den Marketeer. Diese Menschen gestalten, prägen oder beeinflussen einen Markt. Sie sind «echte Macher», marktorientiert denkende Manager und Wissenschaftler oder innovative Unternehmensführer. Mit Portraits von: Julie Blunden, Monique Bourquin, Richard Branson, Christian und Otto Belz, George S. Day, Gottlieb Duttweiler, Hanspeter Egli, Page Rank, Wolfgang Grupp, Heidi, Hans-Olaf Henkel, Uli Hoeness, Steve Jobs, Jürgen Klopp, Dietrich Mateschitz, Elisabeth Noelle-Neumann, Peter Olsson, Erich Sixt, Rupert Stadler, Jimmy Wales, Marcel Walker, Heinz Weinhold, Jörg Zintzmeyer.

Eine gemeinsame Publikation des Marketingdepartements der Universität St.Gallen und von Swiss Marketing (SMC). ISBN 978-3-905819-19-9. CHF 54.-/EUR 37.- (zzgl.Versand), www.thexis.ch 